\title{
MINDFULNESS DAN VIGOR DENGAN PRESTASI AKADEMIK PADA MAHASISWA DI UNIVERSITAS $X$
}

\author{
Mutiara Mirah Yunita dan Teguh Lesmana \\ Program Studi Psikologi, Universitas Bunda Mulia, Jl. Lodan Raya No. 2, Ancol Jakarta Utara
}

Email: mutiara.mirah@gmail.com

\begin{abstract}
Abstrak
Data menunjukkan bahwa beberapa mahasiswa mengalami kegagalan dalam perkuliahan dan kegagalan dalam perkuliahan yang berdampak pada putus kuliah perlu dicari penyebabnya. Salah satu factor awal yang berkontribusi terhadap kegagalan dalam perkuliahan adalah nilai IPK yang rendah. Mahasiswa perlu memiliki cara untuk memiliki sikap belajar yang positif sehingga dapat berkontribusi terhadap peningkatan IPK yang dimiliki. Peneliti ingin mencari tahu manfaat mindfulness dan vigor terhadap IPK mahasiswa, selain mencari tahu hubungan antara mindfulness dan vigor. Metode penelitian menggunakan analisis korelasi untuk menemukan bukti atas hubungan mindfulness dengan vigor, dan prestasi akademik. Jumlah sampel yang digunakan adalah sebanyak 81 mahasiswa dari Universitas X. Mindfulness diukur dengan menggunakan Five Facet Mindfulness Questionnaires (FFMQ), vigor diukur dengan menggunakan Shirom-Melamed vigor measure (SMVM) dan prestasi akademik diukur dengan IPK mahasiswa. Kedua alat ukur sudah diadaptasi, dan hasil reliabilitas sudah baik berdasarkan proses uji coba. Hasil penelitian ini menunjukkan bahwa terdapat hubungan antara mindfulness dan vigor. Hasil analisis lainnya juga menunjukkan terdapat hubungan signifikan antara mindfulness dan vigor dengan prestasi akademik pada mahasiswa.
\end{abstract}

Kata Kunci: Mindfulness, Vigor, Prestasi Akademik

\section{MINDFULNESS AND VIGOR WITH ACADEMIC ACHIEVEMENT AMONG COLLEGE STUDENTS IN X UNIVERSITY}

\begin{abstract}
The data shows that some students have experienced failure in lectures and failures in lectures that have an impact on dropping out of college need to be found. One of the initial factors that contributed to failure in lectures was a low GPA. Students need to have a way to have a positive learning attitude so that they can contribute to improving their GPA. In this case the researcher aims to find out the benefit of mindfulness and vigor towards the student GPA, in addition to finding out the relationship between mindfulness and vigor. The method used in this study is the correlation analysis technique to find relationship evidence of mindfulness with vigor, and academic achievement. The number of samples used was 81 students from University X. Mindfulness was measured using the Five Facet Mindfulness Questionnaires (FFMQ), vigor measured using the ShiromMelamed vigor measure (SMVM) and academic achievement was measured by student GPA. Both measuring instruments have been adapted into Indonesian, and have good reliability based on the trial process. Results of this study indicate a relationship between mindfulness and vigor. Other analysis results also show a significant relationship between mindfulness and vigor with academic achievement in students.
\end{abstract}

Keywords: Mindfulness, Vigor, GPA 


\section{Pendahuluan}

Berdasarkan data dari kemenristekdikti (2017), ditemukan bahwa mahasiswa yang mengalami putus kuliah (drop out) di Indonesia adalah sebanyak 187.798 (4.0\%) anak dari jumlah mahasiswa yang terdaftar sebanyak 4.712.843. Hal ini menunjukkan bahwa masih terdapat hal yang perlu dikaji kembali mengenai penyebab mahasiswa mengalami kegagalan dalam perkuliahan. Salah satu contoh kasus kegagalan dalam perkuliahan terjadi di Universitas Negeri Makassar dimana sebanyak 2.434 mahasiswa angkatan 2011-2016 diberhentikan dari kuliah karena memiliki IPK di bawah 2.00 (Munsir, 2018). Menurut Nurfuadah (2015) terdapat beberapa penyebab mahasiswa mengalami masalah dengan IPK seperti kebiasaan menunda belajar, tidak menyukai materi kuliah, tidak memahami materi kuliah, dan memiliki masalah kesehatan mental. Salah satu universitas yakni Universitas $X$ dalam program studi psikologi ditemukan terdapat beberapa mahasiswa dengan nilai IPK lebih rendah dari 2.00 dan sebanyak 8 orang mahasiswa yang merupakan angkatan 2011 telah diberhentikan (drop out) karena masa studi yang sudah habis. Pada mahasiswa yang diberhentikan, masalah yang nyata adalah nilai IPK yang berada di bawah 2.00 dan keengganan dari mahasiswa untuk kembali melanjutkan kuliah karena masalah nilai IPK yang rendah tersebut.

Menurut Susanti (2015), terdapat beberapa cara yang dapat dilakukan untuk dapat meningkatkan nilai IPK yaitu memiliki disiplin diri, mengerjakan tugas dengan baik, belajar dengan mengulang materi perkuliahan dan senantiasa rajin masuk kuliah. Untuk kegiatan belajar, mahasiswa perlu memiliki motivasi yang konsisten. Menurut Meinarno (2019) keberhasilan kondisi belajar seorang mahasiswa amat bergantung dari diri mahasiswa. Di perguruan tinggi banyak hal yang menarik dan meningkatnya aktivitas. Dengan adanya tantangan yang harus dihadapi, mahasiswa harus menciptakan kondisi yang dapat membuatnya mampu tetap berprestasi sambil menjaga kestabilan kehidupan di dalam maupun di luar perkuliahannya. Kondisi yang diciptakan demikian merupakan kondisi yang dinamakan motivasi. Meskipun demikian motivasi tidak selalu menjadi dasar pendorong atau penggerak dalam kegiatan belajar mahasiswa.

Untuk dapat memiliki hasil yang baik atas kegiatan yang sedang dilakukan, dibutuhkan unsur vigor dalam diri individu dan ini dibuktikan berdasarkan hasil penelitian Isoard-Gautheur, Scotto-di-Luzio, Ginoux, dan Sarrazin (2018) yang menunjukkan bahwa tingkat vigor yang tinggi memiliki potensi untuk mendorong individu terlibat penuh dalam aktivitas kegiatan yang membutuhkan tenaga fisik moderat hingga tinggi. Menurut Shirom (2003), Vigor merupakan konsep yang positif, suatu pengalaman afektif yang dicirikan sebagai kekuatan fisik, energi dari emosi, dan aktivitas kognitif yang berkaitan dengan lingkungan kerja, meskipun dapat dialami di dalam domain kehidupan.

Dalam dunia pendidikan khususnya di perguruan tinggi, ada ciri yang harus dimiliki oleh mahasiswa dalam perguruan tinggi seperti harus dapat mandiri, mampu memberikan motivasi terhadap diri sendiri dan mampu memberikan dorongan terhadap diri untuk bekerja sendiri (Takwin, et al., dalam Meinarno, 2019). Kondisi ini biasanya akan sulit tercapai apabila mahasiswa belum memiliki vigor agar mahasiswa dapat terus memperjuangkan hasil prestasi yang maksimal dalam perkuliahannya. Selain vigor, factor personal yang terbukti dapat meningkatkan prestasi belajar adalah mindfulness (Scherer, Talley, dan Fife, 2017). Dalam penelitian lainnya (Rosentreich \& Margalit, 2015) ditemukan bahwa pada mahasiswa yang sudah diberikan pelatihan mindfulness akan lebih memiliki daya ingat yang baik untuk membantu belajar para mahasiswa dibanding mahasiswa yang tidak mendapat pelatihan mindfulness. Hal ini dikarenakan dengan mindfulness, segala kegiatan 
aktivitas belajar yang dilakukan oleh mahasiswa dilakukan dengan penuh kesadaran sehingga perhatian mahasiswa hanya terfokus pada kegiatan belajar yang sedang dilakukan.

Mindfulness dideskripsikan oleh Naik, Harris dan Fortun (2013) sebagai suatu kondisi yang memiliki tiga karakteristik kunci yakni: (1) memiliki tujuan, (2) sepenuhnya hadir, dan (3) penerimaan. Memiliki tujuan berarti ketika berada dalam kondisi mindfulness maka seseorang secara sengaja dan bertujuan mengarahkan perhatiannya pada satu hal dibanding mengarahkan perhatiannya ke berbagai macam hal. Sepenuhnya hadir berarti ketika dalam kondisi mindfulness maka seseorang hanya memfokuskan pikiran dan perhatiannya pada suatu aktivitas dan tidak terlalu memikirkan apa yang sudah terjadi ataupun yang belum terjadi. Penerimaan berarti mindfulness melibatkan seseorang untuk tidak memiliki penilaian terhadap apapun yang terjadi dalam kehidupannya, baik itu penilaian negatif ataupun positif, sehingga peristiwa yang terjadi hanya diterima sebagai bagian kehidupan.

Dengan menerapkan mindfulness, individu dapat lebih memiliki emosi yang positif, di mana emosi yang positif ini, aktifitas kognitif yang lebih terarah dimana hal ini dapat meningkatkan vigor dalam diri individu. Berdasarkan fenomena yang sudah dipaparkan, maka jika kondisi mindfulness dapat diterapkan dalam kehidupan sehari-hari dan dapat meningkatkan vigor maka diharapkan dapat meningkatkan performa akademik pada mahasiswa dan dapat mengurangi jumlah mahasiswa yang gagal dalam perkuliahan menjadi landasan yang melatarbelakangi penelitian ini untuk dilakukan.

\section{Tinjauan Literatur}

\section{Pengertian Mindfulness}

Menurut Langer (1989), mindfulness dideskripsikan sebagai keterhubungan dan keadaan pikiran aktif yang dicapai dengan memperhatikan hal baru. "Mindfulness adalah memberi perhatian pada pengalaman yang sedang berlangsung pada diri sendiri dalam suatu cara yang memperbolehkan keterbukaan dan fleksibilitas. Mindfulness adalah kondisi yang sepenuhnya hadir dan sadar selama aktivitas sehari-hari yang sedang dilakukan" (Compton, 2005). Menurut Alidina (2010), mindfulness berarti memberi perhatian terhadap sesuatu yang hadir pada saat tertentu dengan suatu tujuan yang disertai dengan rasa terharu, keingintahuan, dan penerimaan.

Mindfulness adalah kebiasaan untuk memberi perhatian, dengan memahami fokus atensi dan arah fokus atensi tersebut diarahkan (McKenzie \& Hassed, 2012). Didonna (2009) menjelaskan, mindfulness sebagai cara untuk mencari hubungan antara semua pengalaman yang sudah dialami untuk mempermudah tantangan yang dihadapi dan membentuk individu menjadi karakter yang lebih baik.

Berdasarkan teori-teori tersebut, dapat disimpulkan bahwa mindfulness adalah keadaan pikiran aktif yang memperhatikan hal-hal baru dan pengalaman hidup secara terbuka dan fleksibel, serta usaha untuk mengurangi kesulitan yang dialami dan berusaha membuat manusia menjadi pribadi yang lebih baik. Mindfulness juga berarti kesadaran individu yang sepenuhnya hadir untuk mengetahui fokus perhatian dan arah perhatian diarahkan dalam setiap aktivitas sehari-hari yang sedang dilakukan.

Untuk lebih mendapatkan gambaran tentang mindfulness, sangatlah berguna untuk menggambarkan juga keadaan sebaliknya, yaitu mindlessness. Ketika seseorang berada dalam kondisi mindless, pikiran orang tersebut tidak fokus, tidak memperhatikan apa yang terjadi di sekitar diri sendiri; singkatnya, orang tersebut melamun. Kondisi melamun ini sebenarnya terkadang 
berguna. Akanlah sangat sulit untuk secara aktif memproses semua informasi yang datang pada diri setiap waktu dalam satu hari. Ketika masuk dalam keadaan mindlessness kronis, maka seseorang akan berada dalam kondisi automatic pilot dan merespon sesuai kebiasaan terhadap dunianya tanpa memikirkan apa yang dilakukan atau diucapkan. Aspek lain dari mindlessness adalah bahwa dalam keadaan tersebut seseorang menjadi terlalu bergantung pada kategori-kategori pengalaman yang terlalu kaku dan mungkin menghambat kemampuan orang tersebut dalam memberi respon secara masuk akal. Berdasarkan eksperimen yang dilakukan Langer (1989), sumber mindlessness ditemukan dalam kebiasaan, premature cognitive commitment pada kategori-kategori yang ada, dan fokus pada tujuan masa depan daripada proses yang berlangsung (Compton, 2005).

\section{Dimensi Mindfulness}

Untuk menggambarkan mindfulness maka digunakan lima aspek dalam Five Facet Mindfulness Questionnaires (FFMQ). Empat aspek FFMQ berasal dari The Kentucky Inventory of Mindfulness Skills (KIMS) yang menggambarkan bahwa kemampuan mindfulness terdiri atas (a) observing/noticing/attending to sensation/perception/thoughts/feelings (b) describing/labelling with words (c) acting with awareness/automatic pilot/concentration/nondistraction, dan (d) accepting (or allowing) without judgment of experiece. Aspek berikutnya yang ditemukan dalam FFMQ adalah aspek (e) nonreactivity to inner experience (Baer, Smith, Hopkins, Krietemeyer, \& Toney, 2006).

Observing/noticing/attending to sensation/perception/thoughts/feelings. Pentingnya observasi selalu ditekankan dalam menggambarkan kondisi mindfulness, yang berarti menyadari berbagai macam stimuli yang datang termasuk di antaranya pikiran, perasaan, sensasi yang dirasakan di tubuh dan juga kejadian di luar seperti bau dan suara dari lingkungan. Dalam aspek ini, praktisi didorong untuk memperhatikan dengan baik terhadap elemen-elemen seperti lokasi, intensitas, durasi dari sensasi, dan intonasi, volume, serta kualitas nada suatu suara (Baer, Smith, \& Allen, 2004).

Describing/labelling with words. Pengertian penerapan kondisi mindfulness disarankan dengan mengobservasi dengan tidak memberi makna label, namun beberapa diskusi tentang mindfulness mengupayakan penggambaran, memberi label atau memberi perhatian terhadap fenomena dengan cara observasi yang melibatkan penerapan kata yang bermakna tertutup. Label dapat berupa kata seperti "sadness" dan "thinking," ungkapan seperti "worrying about my job," atau seperti "Ah, here is anger." Ketika pola pemikiran repetitif diobservasi, beberapa ahli menyarankan suatu perbandingan untuk pemikiran yang muncul berulang-ulang di kepala, dan praktisi didorong untuk memberi label pada pikiran tersebut, Sebagai contoh, praktisi mungkin mengatakan "here's my 'no one appreciates me' tape," atau "this is my 'what a fool I am' tape". Tipe penggambaran semacam ini dilakukan secara tidak mengadili, dan tanpa adanya analisis konseptual. Yakni, partisipan didorong untuk menahan diri dari penilaian (contoh: "it's stupid to think this way") dan dari spekulasi tentang asal usul pola ini. Sebaliknya, mereka diminta untuk melabel pikiran tersebut secara singkat dan melanjutkan perhatian pada keadaan saat masa kini (Baer et al., 2004).

Acting with awareness/automatic pilot/concentration/nondistraction. Mindfulness berarti melibatkan diri secara penuh tanpa membagi perhatian untuk fokus penuh pada satu aktivitas yang dilakukan dalam satu waktu. Dalam Mindfulness Based Cognitive Therapy (MCBT), bertindak dengan kesadaran berlawanan dengan konsep dari "automatic pilot" dimana perilaku terjadi tanpa kesadaran karena perhatian terfokus pada hal lain. Praktisi mindfulness didorong untuk mengembangkan kemampuan ini dalam rutinitas sehari-hari seperti menggosok gigi atau mencuci 
piring dengan cara melibatkan diri seutuhnya dalam aktivitas yang dilakukan dan memfokuskan diri untuk melakukan satu hal dalam satu waktu (Baer et al., 2004).

Accepting (or allowing) without judgment of experiece. Kondisi mindfulness juga dilihat sebagai kondisi yang menekankan pada penerimaan, memperbolehkan, atau menjadi tanpa mengadili atau tanpa pemberian nilai pada apapun yang dialami pada waktu saat kejadian sedang berlangsung. Cara menerima tanpa memberi makna nilai berarti mampu melakukan penahanan diri terhadap pemberian label yang bermakna evaluasi seperti baik dan buruk, benar dan salah, bermakna dan tidak bermakna; kemudian dapat memperbolehkan kenyataan untuk berlangsung sesuai apa adanya tanpa ada usaha untuk mengubah atau menghindari kenyataan tersebut. Dalam praktek klinis, mindfulness sering didorong ketika partisipan dihadapkan pada pengalaman yang tidak diinginkan, seperti perasaan, pikiran, dan sensasi yang tidak menyenangkan. Mengenali dan mengakui kehadiran fenomena ini dan memperbolehkan fenomena tersebut ada apa adanya tanpa langsung bergegas untuk mengubah atau menghilangkan mereka adalah penting untuk kemampuan ini. Nonjudging sering digabungkan dengan mengamati dan menggambarkan. Ketika dihadapkan pada pengalaman yang tidak diinginkan, partisipan didorong untuk mengamati secara hati-hati, memberi label pengalaman tidak diinginkan, dan mengizinkan pengalaman itu untuk ada tanpa penilaian atau mengkritik diri sendiri. Nonjudging bukan berarti menyerahkan diri sepenuhnya pasrah atau berdiam diri. Sebaliknya, nonjudging dipercaya untuk menangani perilaku yang bersifat impulsif, tanpa kontrol, ataupun otomatis yang sifatnya tidak baik untuk invididu (Baer et al., 2004).

Nonreactivity to inner experience. Mindfulness juga dihubungkan dengan kecenderungan untuk mengubah pola pikiran dan perasaan agar pikiran dan perasaan tersebut tidak selalu menjadi fokus utama dalam hidup. Hal ini berarti juga membiarkan pikiran dan perasaan tersebut untuk meninggalkan diri individu agar individu tidak memfokuskan diri secara berlebihan terhadap pikiran dan perasaan yang datang tersebut. (Baer, et al.,2008).

\section{Faktor-Faktor yang Mempengaruhi Mindfulness}

Menurut Langer (1989) terdapat beberapa kualitas kunci dari keadaan mindful yaitu: (a) Pembuatan kategori baru. Keadaan mindful berarti tidak bergantung pada informasi lama dan senantiasa membuat kategori baru dari situasi dan konteks yang dialami. (b) Keterbukaan terhadap informasi baru. Sama halnya dengan membuat kategori baru, keadaan mindful juga berarti senantiasa selalu menerima informasi baru yang ditemui. (c) Kesadaran tentang adanya lebih dari satu sudut pandang. Keterbukaan tidak hanya pada informasi baru, tetapi juga pada sudut pandang yang berbeda merupakan fitur penting dari mindfulness. (d) Kontrol atas konteks. Dengan pembuatan kategori baru, menerima informasi baru, dan melihat lebih dari satu sudut pandang, maka seseorang dapat memiliki kontrol untuk mengubah konteks dari situasi yang dirasa sulit menjadi sesuatu yang mudah. (e) Proses sebelum hasil. Mindfulness adalah sebagai orientasi proses dan proses orientasi sesungguhnya juga berarti menjadi sadar bahwa setiap hasil didahului oleh proses.

Menurut Shapiro, dan Carlson (2009), terdapat 3 komponen utama dari bagaimana cara mindfulness bekerja yaitu: (1) intention, (2) attention, (3) attitude (IAA). Definisi mindfulness yang sering dikutip" - paying attention in a particular way: on purpose, in the present moment, and nonjudgmentally" (Kabat-Zinn dalam Shapiro, \& Carlson, 2009)-mewujudkan tiga komponen mindfulness ini: (1) "on purpose" atau intention, (2) "paying attention" atau attention, (3) "in a 
particular way" atau attitude (kualitas mindfulness). Ketika IAA secara bersama-sama diperkuat maka keadaan mindfulness diasumsikan dapat muncul. Melalui proses ini, reperceiving muncul, yang kemudian memfasilitasi pergantian dalam cara pandang. Reperceiving terjadi ketika secara bertujuan (I) memperhatikan (A) dengan keterbukaan dan tidak mengadili (A) membawa perubahan yang signifikan dalam cara pandang. Pergantian cara pandang ini dianggap sebagai inti dari perubahan dan transformasi yang dipengaruhi oleh latihan mindfulness. Diasumsikan beberapa mekanisme dapat terfasilitasi dengan pergantian pandangan ini, termasuk didalamnya: (a) self-regulation, (b) values clarification, (c) cognitive behavioral flexibility, dan (d) exposure.

\section{Pengertian Vigor}

Vigor merupakan konsep utama yang digunakan dalam konteks pekerjaan. Shirom (2003) mendefinisikan vigor sebagai konsep yang positif, suatu pengalaman afektif yang dicirikan sebagai kekuatan fisik, energi dari emosi, dan aktivitas kognitif yang berkaitan dengan lingkungan kerja, meskipun dapat dialami di dalam domain kehidupan. Vigor merupakan bentuk yang berbeda dari afek positif seperti antusiasme, kesenangan, kenyamanan dan komitmen (Russel \& Steinger, 1982). Ini merupakan kombinasi dari karakteristik emosi dan mood, dan merefer kepada tahap afeksi. Sebagai tambahan Shirom (2011) menyebut bahwa kekuatan fisik memiliki korelasi yang signifikan dengan kapasitas fisik, energi emosional yang merefer kepada kemampuan untuk mengekpresikan empati dan simpati, serta aktifitas kognitif berfokus kepada flow dari proses berpikir dan mental agility.

Karakteristik dari lingkungan kerja seperti tugas yang signifikan, feedback dari supervisor, dan interaksi dengan orang lain ditemukan mempengaruhi vigor. Selain itu juga terdapat peran kepemimpinan, energi kepemimpinan cenderung ditujukan untuk mendorong perasaan energi antara pengikut mereka. Fredrickson (2004) membangun suatu teori broaden-and-built yang mengatakan bahwa emosi positif dapat mengembangkan aktifitas berpikir yang menyebabkan individu menjadi lebih aktif dan membangun sumber daya mengatasi kemunduran emosi. Shirom menggunakan broaden-and-built teori untuk menjelaskan bagaimana emosi yang positif memiliki korelasi dengan vigor dapat menjadi bermanfaat. Vigor juga memiliki hubungan yang positif terhadap motivasi kerja, dan menentukan usaha individu untuk menyelesaikan setiap bagian dari tugas-tugasnya (Shirom, 2007). Hal ini juga dapat memprediksikan performa kerja individu sebagai karyawan (Carmeli, Ben-Hador, Waldman \& Rupp, 2009). Secara lebih vigor juga dapat memprediksikan kesehatan fisik, kesehatan mental, dan performa akademik (Shirom, 2011).

\section{Hipotesis}

Hipotesis dalam penelitian ini terdiri atas:

- H1: mindfulness dapat berhubungan secara signifikan terhadap vigor pada mahasiswa Universitas $\mathrm{X}$.

- H2: mindfulness dapat berhubungan secara signifikan terhadap prestasi akademik pada mahasiswa Universitas $X$.

- H3: vigor dapat berhubungan secara signifikan terhadap prestasi akademik pada mahasiswa Universitas $\mathrm{X}$. 


\section{Tujuan Penelitian Dilakukan}

Penelitian bertujuan untuk mencari tahu hubungan mindfulness dan vigor dengan prestasi akademik pada mahasiswa program studi psikologi Universitas $\mathrm{X}$.

\section{Metode Penelitian}

\section{Partisipan Penelitian}

Subjek dari penelitian ini adalah 81 orang mahasiswa yang berusia antara $16-25$ tahun ( $M=19.99$ ) yang merupakan mahasiswa program studi psikologi dari salah satu Universitas di kota DKI Jakarta. Metode sampling adalah convenience sampling technique. Dari 81 subjek penelitian, 60 orang diantaranya (74.1\%) berjenis kelamin perempuan. Peneliti menyebarkan kuesioner secara langsung dengan memberikan kuesioner kepada para mahasiswa yang sedang belajar di kelas. Mahasiswa yang terlibat menjadi sampel dalam penelitian ini merupakan mahasiswa aktif yang masih mengikuti perkuliahan dan salah satu tujuan menyebarkan di kelas saat sedang belajar adalah untuk memastikan mahasiswa yang terlibat dalam penelitian ini merupakan mahasiswa aktif yang masih rutin mengikuti perkuliahan.

\section{Instrumen Penelitian}

Kuesioner mindfulness yang digunakan dalam bentuk likert yang menghasilkan data interval yang terdiri dari skala 1-4 pernyataan masing-masing sebagai berikut: (1) sangat tidak sesuai (STS); (2) tidak sesuai (TS); (3) sesuai (S); (4) sangat sesuai (SS). Sementara untuk alat ukur Vigor menggunakan bentuk skala likert juga yang menghasilkan data interval yang terdiri dari skala 1-7 dengan pilihan jawaban masing-masing sebagai berikut: (1) tidak pernah (TP); (2) sangat jarang (SJ); (3) jarang (J); (4) kadang-kadang (KK); (5) sering (SR); (6) sangat sering (SS); dan (7) selalu (SL).

Mindfulness dalam penelitian ini diukur menggunakan Five facet Mindfulness Questionnaires (FFMQ) milik Baer et al. (2006) sudah diadaptasi ke Bahasa Indonesia oleh peneliti dan kuesioner ini menggambarkan bahwa kemampuan mindfulness terdiri atas (a) nonreactivity to inner experience, (b) observing, (c) acting with awareness, dan (d) describing, dan (e) accepting (or allowing) without judgment. Vigor diukur dengan menggunakan Shirom-Melamed vigor measure (SMVM) milik Shirom (2004) yang telah diadaptasi ke dalam Bahasa Indonesia oleh peneliti dan alat ukur ini menggambarkan unsur vigor terdiri atas (a) Physical strength, (b) Emotional energy, dan (c) Cognitive Liveliness. Sedangkan untuk mengukur perfoma akademik dengan menggunakan IPK mahasiswa. Pengolahan data dengan menggunakan SPSS 21.

Hasil uji coba adaptasi alat ukur menggunakan 57 responden menunjukkan bahwa reliabilitas alat ukur mindfulness dan vigor yang sudah diadaptasi ke Bahasa Indonesia layak untuk digunakan. Hasil reliabilitas FFMQ dapat dilihat pada Tabel 1 dan hasil reliabilitas SMVM dapat dilihat pada Tabel 2.

Tabel 1. Hasil Reliabilitas FFMQ

\begin{tabular}{ccc}
\hline Dimensi & Cronbach Alpha & Item \\
\hline Nonreactivity & 0.801 & 7 \\
Observing & 0.853 & 11 \\
Act Aware & 0.850 & 23 \\
Describing & 0.814 & 7 \\
Nonjudgment & 0.825 & 9 \\
\hline \multicolumn{2}{c}{ Total Item } & 57 \\
\hline
\end{tabular}


Tabel 2. Hasil Reliabilitas SMVM

\begin{tabular}{ccc}
\hline Dimensi & Cronbach Alpha & Item \\
\hline $\begin{array}{c}\text { Physical strength } \\
\text { Emotional } \\
\begin{array}{c}\text { Energy } \\
\text { Cognitive } \\
\text { Liveliness }\end{array}\end{array}$ & 0.870 & 5 \\
\multicolumn{2}{c}{ Total Item } & 4 \\
\hline
\end{tabular}

\section{Prosedur Penelitian}

Sebelum penyebaran data, peneliti menguji coba terlebih dahulu alat ukur yang digunakan untuk mengumpulkan data. Setelah melalui proses uji coba, kemudian peneliti baru menggunakan alat ukur yang sudah diadaptasi ke bahasa Indonesia oleh peneliti. Kuesioner dibagikan secara fisik kepada para mahasiswa aktif program studi psikologi Universitas X ketika dalam kegiatan belajar di kelas, setelah kegiatan belajar selesai dilakukan, maka para mahasiswa diminta partisipasinya untuk mengisi kuesioner yang diberikan peneliti. Peneliti sebelumnya terlebih dahulu meminta izin kepada pimpinan program studi psikologi Universitas $X$ untuk menyebarkan kuesioner dan menjelaskan tujuan penelitian kepada pimpinan program studi. Setelah mendapatkan izin, peneliti baru menyebarkan kuesioner kepada para mahasiswa yang di dalamnya sudah ada informed consent untuk meminta kesediaan mahasiswa terlibat dalam penelitian yang akan dilakukan oleh peneliti.

\section{Analisis Data}

Penelitian menggunakan jenis penelitian kuantitatif dengan metode korelasi yang memiliki tujuan untuk menguji hubungan antara dua variabel. Variabel-variabel dalam penelitian ini terdiri atas mindfulness, vigor, dan prestasi akademik mahasiswa. Penelitian ini menggunakan analisis korelasi dengan menggunakan program SPSS untuk mendapatkan hasil data analisis korelasi antar variable yang diuji.

\section{Hasil Penelitian}

Sebelum melakukan pengujian hipotesis dengan menggunakan uji korelasi, peneliti menguji normalitas data terlebih dahulu. Peneliti menguji normalitas data dengan one-sample KS lewat program SPSS. Hasil dari uji normalitas menunjukkan data pada variabel mindfulness terdistribusi normal ( $p=0.658>0.05)$, dan data pada variabel vigor juga terdistribusi normal $(p=0.712>0.05)$. Menurut Nisfianoor (2009), bila data terdistribusi normal maka teknik analisis korelasi Pearson digunakan, sementara bila data terdistribusi tidak normal maka yang digunakan adalah teknik korelasi Spearman. Dalam data penelitian ini karena data terdistribusi normal maka yang digunakan adalah teknik korelasi Pearson.

Hasil Uji Normalitas data penelitian yang berjumlah 81 orang menunjukkan bahwa baik data mindfulness dan vigor memiliki distribusi normal karena nilai sig diatas 0.05 dengan mindfulness memiliki nilai sig $=0.658$ dan vigor memiliki nilai sig $=0.712$. Dengan demikian teknik analisis korelasi yang digunakan adalah korelasi Pearson untuk distribusi data normal. Berikut merupakan tabel yang merangkum gambaran mindfulness, vigor, dan IPK mahasiswa. 
Tabel 3. Analisis Deskriptif Variabel

\begin{tabular}{ccccc}
\hline Variabel & $\mathrm{N}$ & Min & Maks & Mean \\
\hline Mindfulness & 81 & 1.83 & 3.44 & 2.70 \\
Vigor & 81 & 2.00 & 6.56 & 4.48 \\
IPK & 81 & 1.89 & 3.65 & 3.03 \\
\hline
\end{tabular}

Hasil analisis menunjukkan nilai mindfulness di tingkat tinggi karena nilai mean empirik yang lebih tinggi dari mean hipotetik yang menggunakan nilai tengah 2,5 pada skala 1-4. Dengan demikian hal ini menunjukkan bahwa partisipan memiliki kecenderungan mindfulness yang tinggi. Sementara nilai pada vigor menunjukkan berada di tingkat tinggi karena nilai mean empirik yang lebih tinggi dari mean hipotetik yang menggunakan nilai tengah 4 pada skala 1-7. Hasil ini menunjukkan bahwa partisipan cenderung memiliki kecenderungan vigor yang tinggi.

Berdasarkan analisis korelasi ditemukan hubungan positif signifikan antara mindfulness dengan vigor $\left(p=0.002, r=0.334^{* *}\right)$. Sehingga semakin tinggi mindfulness, maka vigor yang dimiliki juga semakin tinggi, sebaliknya mindfulness yang semakin rendah, maka vigor yang dimiliki semakin rendah juga. Mindfulness memiliki nilai korelasi $r=0.299$ yang berarti $29.9 \%$ mindfulness memiliki sumbangsih terhadap vigor. Pada hasil analisis korelasi selanjutnya juga ditemukan bahwa terdapat hubungan positif yang signifikan antara mindfulness dengan IPK mahasiswa $\left(p=0.00, r=0.593^{* *}\right)$ dan vigor dengan IPK mahasiswa $\left(p=0.007, r=0.300^{* *}\right)$, sehingga baik mindfulness dan vigor ditemukan dapat berkontribusi secara positif terhadap IPK mahasiswa. Jadi semakin tinggi mindfulness dan vigor yang dimiliki oleh mahasiswa maka semakin tinggi pula IPK mahasiswa, sebaliknya semakin rendahnya mindfulness dan vigor yang dimiliki mahasiswa akan semakin rendah pula IPK mahasiswa. Mindfulness memiliki nilai korelasi $r=0.593$ yang berarti $59.3 \%$ mindfulness memiliki sumbangsih terhadap IPK, sementara vigor memiliki nilai korelasi $r=0.300$ yang berarti $30 \%$ vigor memiliki sumbangsih terhadap IPK.

\section{Pembahasan}

Hubungan antara mindfulness dengan vigor dalam penelitian didukung oleh hasil penelitian Dane dan Brummel (2013) yang menemukan hasil bahwa mindfulness terbukti dapat berhubungan positif dengan salah satu dimensi work engagement yakni vigor. Dalam penelitian Dane dan Brummel (2013) dijelaskan bahwa mindfulness dapat berkontribusi terhadap vigor karyawan ketika bekerja karena mindfulness membantu karyawan untuk tetap fokus dalam kegiatan bekerjanya di waktu kerja tanpa memikirkan hal lain selain pekerjaan yang dilakukan. Fokus terhadap kegiatan yang dikerjakan ini, kemudian dapat meningkatkan semangat (vigor) baik secara fisik, kognitif dan emosional dalam melakukan suatu pekerjaan. Dengan demikian, hasil penelitian ini dapat mengindikasikan bahwa ketika mahasiswa memiliki kondisi mindfulness dalam kegiatan belajar di kelasnya maka mahasiswa dapat lebih memiliki semangat (vigor) dalam melakukan kegiatan belajarnya di kelas.

Hasil penelitian lain (Aikens et al., 2014) juga menunjukkan bahwa mindfulness berkontribusi dalam meningkatkan vigor dalam penelitian yang menggunakan desain penelitian eksperimen. Dalam penelitian tersebut (Aikens et al., 2014) dijelaskan bahwa pelatihan intervensi mindfulness kepada para partisipan dapat meningkatkan vigor dan resiliensi para karyawan yang kemudian menyebabkan 
penurunan tingkat stres yang dialami oleh para karyawan. Dalam penelitian ini, mindfulness hanya diteliti dengan vigor dan tidak dilakukan penelitian hubungan dengan tingkat resiliensi maupun tingkat stress yang dialami oleh mahasiswa, namun hasil hubungan yang positif antara mindfulness dan vigor sudah cukup didukung dengan hasil dan penjelasan dari penelitian sebelumnya.

Hubungan antara mindfulness dengan IPK dalam penelitian ini didukung penelitian dari Teodorczuk, Guse, dan Du Plessis (2016) yang menunjukkan bahwa mindfulness dapat memprediksi hasil tugas akhir mahasiswa dan prestasi akademik mahasiswa. Dalam penelitian Teodorczuk, Guse, dan Du Plessis (2016) dijelaskan bahwa mindfulness dapat berkontribusi terhadap prestasi akademik mahasiswa karena melalui mindfulness para mahasiswa cenderung dapat lebih melakukan kegiatan belajarnya dengan penuh pemaknaan dan menyikapi kegiatan belajar maupun ujian atau tugas kuliah sebagai suatu proses alami yang harus terjadi tanpa memberikan makna apapun terhadap kegiatan yang harus dilakukan. Selain itu melalui mindfulness, maka mahasiswa menjadi lebih memfokuskan pikiran dan perasaannya pada kondisi kekinian tanpa mengingat pengalaman masa lalu ataupun memikirkan kesulitan yang mungkin akan dihadapi di waktu mendatang yang kemudian dapat berpengaruh terhadap nilai prestasi akademik mahasiswa. Hasil penelitian lain (Lin \& Mai, 2016) dengan desain penelitian eksperimen juga menunjukkan bahwa praktek latihan mindfulness dalam bentuk latihan meditasi terbukti dapat meningkatkan prestasi akademik mahasiswa yang berlatih mindfulness dengan meditasi dibanding mahasiswa yang tidak berlatih mindfulness.

Hubungan antara vigor dengan IPK didukung oleh hasil penelitian Crumpacker (2017) yang menunjukkan nilai vigor yang tinggi akan ditemukan pada mahasiswa yang memiliki IPK tinggi dengan rentang antara 3.00-3.49 dan 3.49-4.00. Dalam penelitian Crumpacker (2017) dijelaskan bahwa penyebab vigor dapat berkontribusi positif terhadap IPK mahasiswa karena vigor membantu mahasiswa untuk mengatasi rasa frustrasi ataupun jenuh yang mungkin dialami ketika dalam proses belajar. Lebih lanjut, dengan adanya vigor maka mahasiswa dapat lebih bertahan lama dalam proses belajarnya. Hasil penelitian lain (Cacuso-Holgado, et al., 2013) juga mendukung vigor berkontribusi terhadap IPK dan dalam penelitian tersebut meski yang diteliti adalah academic engagement, namun salah satu dimensi academic engagement, yakni vigor terbukti berkontribusi secara positif dan signifikan terhadap peningkatan IPK pada mahasiswa di bidang ilmu kesehatan.

\section{Kesimpulan}

Penelitian ini menunjukkan mindfulness dapat berhubungan signifikan dengan vigor, dan mindfulness dapat berhubungan signifikan dengan IPK mahasiswa. Mindfulness merupakan kualitas positif dalam diri individu yang mendorong individu untuk fokus dan penuh perhatian dalam segala aktivitas yang dilakukan, sehingga kondisi ini kemudian akan menimbulkan semangat (vigor) dalam diri individu saat beraktivitas ketika aktivitas tersebut dilakukan dengan penuh kesadaran dan fokus (mindfulness). Selain itu, baik mindfulness dan vigor juga terbukti dalam meningkatkan IPK mahasiswa karena kedua variabel saling bersinergi dalam memfokuskan kegiatan belajar yang dilakukan oleh mahasiswa.

\section{Saran}

Saran untuk penelitian selanjutnya adalah meneliti faktor lain selain faktor yang dibahas di penelitian ini yang mungkin dapat berkontribusi pada prestasi akademik mahasiswa. Saran untuk mahasiswa adalah agar dapat mempertahankan semangat (vigor) dan fokus (mindfulness) dalam 
kegiatan belajarnya agar dapat meningkatkan IPK yang dimiliki. Hal ini dapat membantu mahasiswa untuk terhindar dari kegagalan dalam menyelesaikan kuliahnya sehingga mahasiswa tidak akan mengalami kesulitan dalam menjalani kegiatan belajarnya. Cara yang dapat dilakukan untuk meningkatkan mindfulness adalah dengan melakukan latihan relaksasi ataupun meditasi pernapasan sebelum kegiatan belajar dimulai sehingga kegiatan belajar yang akan dilakukan dapat dilakukan dengan penuh fokus dan kesadaran.

\section{Daftar Pustaka}

Aikens, K. A., Astin, J., Pelletier, K. R., Levanovich, K., Baase, C. M., Park, Y. Y., \& Bodnar, C. M. (2014). Mindfulness goes to work: Impact of an online workplace intervention. JOEM, 56(7): 721731. DOI: 10.1097/JOM.0000000000000209

Alidina, S. (2010). Mindfulness for dummies. England, UK: John Wiley \& Sons

Baer, R. A., Smith, G. T., \& Allen, K. B. (2004). Assessment of mindfulness by self-report the kentucky inventory of mindfulness skill. Assessment, 11(1): 191-206.

Baer, R. A., Smith, G. T., Hopkins, J., Krietemeyer, J., \& Toney, L. (2006). Using self-report assessment methods to explore facets of mindfulness. Assessment, 13(1): 27-45.

Baer, R. A., Smith, G. T., Lykins, E., Button, D., Krietemeyer, J., Sauer, S., Walsh, E., Duggan, D., \& Williams, J. M. G. (2008). Construct validity of the five facet mindfulness questionnaire in meditating and nonmeditating samples. Assessment, 15(3): 329-342.

Carmeli, A., Ben-Hador, B., Waldman, D. A., \& Rupp, D. E. (2009). How leaders cultivate social capital and nurture employee vigor: Implications for job performance. Journal of Applied Psychology, 94(6), 1553-1561.

Casuso-Holgado, M. J., Cuesta-Vargas, A. I., Moreno-Morales, N., Labajos-Manzanares, M. T., BarónLópez, F. J., \& Vega-Cuesta, M. (2013). The association between academic engagement and achievement in health sciences students. BMC medical education, 13, 33. doi:10.1186/14726920-13-33

Compton, W. C. (2005). An introduction to positive psychology. Belmont, CA: Wadsworth, a division of Thomson Learning Inc

Crumpacker, Norman. (2017). Relationship between Vigor, Demographic Variables, and Academic Performance. Diunduh dari https://www.researchgate.net/publication/242249806 Relationship between Vigor Demo graphic Variables and Academic Performance

Dane, E., \& Brummel, B. J. (2013). Examining workplace mindfulness and its relations to job performance and turnover intention. Human Relations, 0(0): 1-24. DOI: $10.1177 / 0018726713487753$

Didonna, F. (2009). Clinical handbook of mindfulness. New York, NY: Springer 
Fredrickson B. L. (2004). The broaden-and-build theory of positive emotions. Philosophical transactions of the Royal Society of London. Series B, Biological sciences, 359(1449), 13671378

Kemenristekdikti. (2017). Statistik pendidikan tinggi tahun 2017. Jakarta Pusat: Pusat Data dan Informasi Iptek Dikti.

Langer, E. J. (1989). Mindfulness (a merloyd lawrence book). Cambridge, MA: Da Capo Press

Lin, J. W., \& Mai, L. J. (2016). Impact of mindfulness meditation intervention on academic performance. Innovations in Education and Teaching International, 55(3), 366-375.

McKenzie, S., \& Hassed, C. (2012). Mindfulness for life. Wollombi, NSW: Exisle

Meinarno, E. A. (2019). Berbincang motivasi guna menghadapi kehidupan perguruan tinggi. Buletin K$P I N$, 5(13). Diunduh dari https://buletin.k-pin.org/index.php/daftar-artikel/435-berbincangmotivasi-guna-menghadapi-kehidupan-perguruan-tinggi

Munsir, I. (2018). Universitas negeri Makassar do 2.434 mahasiswa dengan ipk rendah. Diunduh dari https://news.detik.com/berita/d-3918688/universitas-negeri-makassar-do-2434-mahasiswadengan-ipk-rendah

Naik, P., Harris, V. W., \& Forthun, L. F. (2013). Mindfulness: An introduction. Diunduh dari https://www.researchgate.net/publication/261528260 Mindfulness An Introduction

Nisfiannoor, M. (2009). Pendekatan statistika modern untuk ilmu sosial. Jakarta: Salemba Humanika

Nurfuadah, R. N. (2015). Penyebab dan solusi nilai kuliah jelek. Diunduh dari https://news.okezone.com/read/2015/10/02/65/1224653/penyebab-dan-solusi-nilai-kuliahjelek

Rosenstreich, E., \& Margalit, M. (2015). Loneliness, mindfulness, and academic achievements: A moderation effect among first-year college students. The Open Psychology Journal, 2015(8): 138-145.

Russell, J. A., \& Steiger, J. H. (1982). The structure in persons' implicit taxonomy of emotions. Journal of Research in Personality, 16(4), 447-469.

Scherer, S., Talley, C. P., \& Fife, J. E. (2017). How personal factors influence academic behavior and gpa in african American stem students. Sage Open April-June 2017: 1-14.

Shapiro, S. L., \& Carlson, L. E. (2009). The art and science of mindfulness: Integrating mindfulness into psychology and the helping professions,(pp.3-14). Washington, DC, US: American Psychological Association

Shirom, A. (2007). Explaining vigor: on the antecedents and consequences of vigor as a positive affect at work. In D. L. Nelson \& C. L. Cooper (Eds.), Positive organizational behavior (pp. 86-100). London: SAGE Publications Ltd 
Mutiara Mirah Yunita dan Teguh Lesmana

Shirom, A. (2003). Feeling vigorous at work? The construct of vigor and the study of positive affect in organizations. Emotional and Physiological Processes and Positive Intervention Strategies, 135-164.

Shirom, A. (2011). Vigor as a positive affect at work: Conceptualizing vigor, its relations with related constructs, and its anteceents and consequences. Review of General Psychology, 15(1): 5064.

Susanti, A. (2015). Tingkatkan nilai ipk dengan cara simpel. Diunduh dari https://news.okezone.com/read/2015/12/10/65/1264399/tingkatkan-nilai-ipk-dengan-carasimpel

Teodorczuk, Krysia \& Guse, Tharina \& Du Plessis, Graham. (2016). Mindfulness and academic achievement in South African university students. 10.13140/RG.2.1.3307.8169. 